\title{
Determinants of drink-driving and association between drink- driving and road traffic fatalities in Ghana
}

\author{
James Damsere-Derry ${ }^{1,2}$, Francis Afukaar ${ }^{1}$, Gavan Palk ${ }^{2}$, and Mark King ${ }^{2}$ \\ ${ }^{1}$ Building \& Road Research Institute, Ghana \\ ${ }^{2}$ Centre for Accident \& Road Safety Research-Queensland. Queensland University of Technology, Queensland, Australia
}

\begin{abstract}
Aims: The objective is to establish determinants of drink-driving and its association with traffic crashes in Ghana.

Methods: A multivariable logistic regression was used to establish significant determinants of drink-driving, and a bivariate logistic regression to establish the association between drink-driving and road traffic crashes in Ghana.

Results: In total, 2,736 motorists were randomly stopped for breath testing, of whom 8.7\% tested positive for alcohol. Among the total participants, $5.5 \%$ exceeded the legal BAC limit of $0.08 \%$. Formal education is associated with a reduced likelihood of drink-driving compared with drivers without formal education. The propensity to drink-drive is 1.8 times higher among illiterate drivers than it is among drivers with basic education. Young adult drivers also recorded elevated likelihoods for driving under alcohol impairment, compared with adult drivers. The odds of drink-driving among truck drivers is $O R=1.81$ ( $95 \% \mathrm{CI}=1.16$ to 2.82) and two-wheeler riders is $O R=1.41(95 \% \mathrm{CI}=0.47$ to 4.28$)$ compared with car drivers. Contrary to general perception, commercial car drivers have a significant reduced likelihood of $41 \%, O R=0.59(95 \% \mathrm{CI}=0.38$ to 0.92$)$ compared with private car drivers. Bivariate analysis conducted showed a significant association between the proportion of drivers exceeding the legal BAC limit and road traffic fatalities $(p<0.001)$. The model predicts that a $1 \%$ increase in the proportion of drivers exceeding the legal BAC will be associated with a $4 \%$ increase in road traffic fatalities (95\% CI $=3 \%$ to $5 \%$ ) and vice versa.
\end{abstract}

Conclusions: A positive and significant association between roadside alcohol prevalence and road traffic fatality has been established. Scaling up roadside breath tests, determining standard drink (e.g., any drink which contains about 10 grams of absolute alcohol) and disseminating this information to the populace, and formulating policies targeting youth (such as increasing minimum legal drinking age and reducing the legal BAC limit for youth and novice drivers) might reduce drink-driving related crashes in Ghana.

Road traffic crashes (RTCs) are an important global public health pandemic, claiming about 1.3 million lives and injuring up to 70 million people annually (World Health Organization [WHO], 2009, 2011). Current World Health Organization (WHO) statistics available show that a vast majority (80\%) of the world's cars are owned by some $15 \%$ of the world's population, located in North America, Japan, Australia and Western Europe. Nevertheless, the burden of RTCs are disproportionately felt by developing countries with fewer vehicles per population. More than $85 \%$ of road traffic fatalities and $90 \%$ of disability adjusted lost years from road traffic injuries occur in developing countries (Peden et al., 2004).

In countries where road safety research is in advanced stages, impaired driving, particularly drink-driving, has been identified as a major risk factor of road traffic crash frequency and severity (Global Road Safety Partnership, 2007; Longo, Hunter, Lokan, White, \& White, 2000; Wells
\& Macdonald, 1999; WHO, 2009). Most countries which have prioritized alcohol research seem to have found a concurrent decline in drink-driving and its related road traffic injuries and fatalities. According to Chang, $\mathrm{Wu}$, and Ying (2012), in the United States, alcohol related fatalities have significantly declined-from $60 \%$ in 1982 to $40 \%$ in 2006-due to the effectiveness of countermeasures premised on deterrent laws. On the contrary, in some developing countries, no discernible pattern of alcoholrelated research protocols has been established. The paucity of alcohol-related research in some developing countries, particularly in Africa, has been well reported (Mock, Asiamah, \& Amegashie, 2001; Obot, 2000; UNODC, 2013). Evidence of drug and alcohol impairments are hardly ever checked for at traffic crashes in Ghana, except when crashes involve public figures (Owusu Achiaw \& Donkor, 2007). There is, however, evidence suggesting frequent use of alcohol and other drugs

Correspondence: James Damsere-Derry, Building \& Road Research Institute, UPO Box 40, Kumasi, Ghana. Telephone (Cell): +233-246-414961: Fax: +233-322060080: Email: jdamserederry@yahoo.com

Financial support:. Funding was provided by the National Road Safety Commission (NRSC) of Ghana.

Keywords: blood alcohol concentration, commercial car drivers, road traffic fatalities, standard drink, roadside breath test 
among people, particularly adolescents, in Ghana (AduMireku, 2003; Doku, Koivusilta, \& Rimpela, 2012), which suggests the potential involvement of alcohol in traffic crashes. In order to reduce road traffic injuries in Ghana, there is the need to prioritize alcohol impairment research, establish key determinants of drink-driving and their relationship with traffic crashes, and design interventions targeting these risk factors. The objective of this study is to establish the determinants of roadside drink-driving prevalence and its association with road traffic injury severity in Ghana.

\section{Methodology}

A cross-sectional study design was used for the alcohol data collection. There was no prospective or retrospective follow-up of participant drivers on their drinking history. No identifying information regarding the drivers' names, telephone or car numbers was collected.

Sampling technique. Systematic random sampling was used in selecting drivers, in which every fifth vehicle was stopped for breath test and interview. Sampled drivers were generally pulled off the roadway, in order to allow uninterrupted traffic flow at the study sites. Short questionnaires were also administered in the field to capture essential socio-demographic and driving characteristics deemed potential determinants of drinkdriving.

\section{Participation}

Participation in the research was voluntary, and the study team employed internationally approved ethical procedures to protect research participants from being prosecuted. The survey engaged police assistance in stopping and administering the Breath Alcohol Concentration (BrAC) test. Although drunk-drivers were not liable for prosecution, when drivers were excessively drunk (e.g., having BAC of $0.1 \%$ or above) the police advised them to park their vehicles and rest until they regained their sobriety or an alternate driver could be called upon (Mock et al., 2001). Disposable mouthpieces were used for each participant.

\section{Study sites}

The roadside breath tests occurred in five major cities: Accra, Kumasi, Sekondi-Takoradi, Tamale, and Ho. Breath tests also took place on the principal inter-urban highways. The roads selected fall under three categories: National roads, Inter-regional roads, and Regional roads. These are the most traveled roads in the country and are fairly representative of Ghana's road network. Existing road blocks, police check points, and toll booths were used as the study sites. These sites are well known to motorists, and drivers normally slow down either to undergo routine traffic examinations by the police or pay their road toll charges, which are manually operated.

At each location, for each three-hour shift, three people were assigned to be in charge of each direction of traffic flow. Each team consisted of a policeman whose duty was to wave in selected drivers, an interviewer who administered the questionnaires, and a breathalyzer holder who measured breath samples of selected motorists. Few motorists filled in the questionnaires themselves; most were filled in by designated personnel from the research team. Since some of these routes could be very long-up to 1,000 kilometers_road segments were divided into shorter sections. Locations were at the midway point of each road section, which takes approximately an hour to reach-the average time in which one standard drink will disappear from a consumer's blood. A standard drink which is a scientific way of measuring the volume of alcohol an individual has drunk is any drink that contains about 10 grams of pure alcohol.

\section{Study period}

The study occurred between November 2011 and March 2012. The Yuletide period between December 23, 2011 and January 15, 2012 was excluded because of the attendant excessive drinking behavior. At each location, breath tests occurred between 6:00 a.m. and 10:00 p.m., usually for not longer than four hours per urban location and eight hours at inter-urban locations. The police authority recommended this study period for security reasons.

\section{Statistical analysis and crash data source}

The data obtained were first stratified by different degrees of alcohol concentrations (i.e., negative, 0.001-0.05, 0.051-0.08, and 0.081 or above) and important determinants of drink-driving. The phase I analysis predominantly uses univariate and descriptive statistics to determine the magnitude of drink-driving among Ghanaian drivers, and a multivariate logistic regression was used to establish significant predictors of drink-driving. The second phase of the analysis, on the other hand, is based on a bivariate logistic regression to determine the impact of drink-driving on road traffic crash severity.

The crash dataset used was obtained from the Building and Road Research Institute's accident databank (BRRI, 2011), stored using the Micro-computer Accident Analysis Package (MAAP) developed by the Transport Research Laboratory (TRL) of the U.K. The accident form contains 78 fields which describe the crash scenario and victims involved in detail. Even though the crash form provides fields for police to report on alcohol and drug use by road users, this information is always missing. Data on the form are manually entered into the MAAP and can be queried to produce cross-tabulations. The dataset is one year behind time, and it is known that there is a degree of underreporting of less severe crashes (Salifu \& Ackaah, 2009).

\section{Results}

In total, 2,736 drivers were randomly stopped and their $\mathrm{BrAC}$ measured. BrAC figures were converted to BAC using the principle of Henry's Law, based on the partition ratio between blood and breath alcohol concentration of 2,300:1 established in the U.K. (Cowan, Burris, Hughes, \& 
Cunningham, 2010; Haffner, Graw, Dettling, Schmitt, \& Schuff, 2003; University of Dundee, 2011).

Among those drivers whose BrAC were tested, 8.7\% had detectable alcohol in their breath, and 5.5\% exceeded the country's legal BAC limit of $0.08 \%$. Generally, $64 \%$ of the drivers who tested positive for alcohol exceeded the legal limit, $19 \%$ had BAC ranging between $0.05 \%$ and $0.08 \%$, and the remaining $17 \%$ had BAC ranging between $0.001 \%$ and $0.051 \%$. For the category of drivers who were alcohol positive, the mean BAC was 0.136 (95\% CI: 0.122 to $0.152)$.

The majority of drivers in the study (72\%) had only basic education qualifications, while $15 \%$ had up to secondary education, $6 \%$ had no formal education, and $7 \%$ possessed tertiary or post-tertiary education. Table 1 shows that the prevalence rate of drink-driving was highest among drivers who had no formal education; over $10 \%$ of all drivers in this category exceeded the legal limit. Six per cent of all secondary school certificate holders were found to be over the limit, as were $6 \%$ of drivers with tertiary education. Drivers with different levels of formal education were similar in many respects with regard to the incidence of drink-driving. Intra-variable comparison of the educational variable shows that the incidence of drink-driving among drivers with basic education was not statistically different from drivers with secondary school qualification ( $p=$ 0.2564 ) and also not statistically different from drivers with tertiary qualification $(p=0.4433)$. The prevalence rate of drink-driving among drivers with no formal education was significantly higher than drivers with secondary education ( $p=0.0462$ ), but only marginally higher than drivers with tertiary education $(p=0.0747)$.

According to the survey, $78.7 \%$ of the drivers were either married or were in a de facto relationship, $20 \%$ had never married before, $1 \%$ were divorcees, and $0.2 \%$ were widowed. The highest drink-driving prevalence rate, 15\%, was detected among divorcees. The relative incidence of drink-driving among divorcees was significantly higher than never-married drivers $(p=0.0053)$ and higher than currently married drivers $(p=0.02)$. There was, however, no statistical difference in drink-driving prevalence among married drivers versus never-married drivers $(p=0.1454)$.

The male-female ratio for drivers sampled in the BrAC test was $98 \%$ to $2 \%$ respectively, showing low female participation in driving in the country. Among the females surveyed, none had detectable alcohol in their breath.

Table 1

Socio-economic determinants of drink-driving in Ghana

\begin{tabular}{|c|c|c|c|c|c|c|c|c|c|}
\hline \multirow[b]{3}{*}{ Variables } & \multicolumn{9}{|c|}{ Blood Alcohol Concentration Levels } \\
\hline & \multirow[b]{2}{*}{ Total } & \multicolumn{2}{|c|}{ Negative } & \multicolumn{2}{|c|}{$0.001-0.05$} & \multicolumn{2}{|c|}{$0.051-0.08$} & \multicolumn{2}{|c|}{$>0.08$} \\
\hline & & No. & $(\%)$ & No. & $(\%)$ & No. & $(\%)$ & No. & $(\%)$ \\
\hline \multicolumn{10}{|l|}{ Drivers' age } \\
\hline $18-29$ & 688 & 652 & $(94.8)$ & 5 & $(0.7)$ & 8 & $(1.2)$ & 23 & (3.3) \\
\hline $30-39$ & 1,148 & 1,053 & $(91.7)$ & 18 & $(1.6)$ & 21 & $(3.1)$ & 56 & (4.9) \\
\hline $40-49$ & 654 & 586 & $(89.6)$ & 13 & $(2.0)$ & 9 & $(1.3)$ & 46 & $(7.0)$ \\
\hline $50-59$ & 207 & 173 & $(83.6)$ & 3 & $(1.4)$ & 8 & $(1.2)$ & 23 & (11.1) \\
\hline $60-72$ & 39 & 36 & $(92.3)$ & 0 & 0.0 & 0 & 0.0 & 3 & (7.7) \\
\hline Total & 2,736 & 2,500 & (91.4) & 39 & (1.4) & 46 & (1.7) & 151 & (5.5) \\
\hline \multicolumn{10}{|l|}{ Educational Level } \\
\hline None & 165 & 140 & $(84.8)$ & 4 & (2.4) & 4 & $(2.4)$ & 17 & (10.3) \\
\hline Basic & 1,960 & 1,810 & (92.3) & 23 & $(1.2)$ & 31 & (1.6) & 96 & (4.9) \\
\hline Secondary & 416 & 373 & (89.7) & 8 & (1.9) & 9 & $(2.2)$ & 26 & (6.3) \\
\hline Tertiary & 195 & 177 & $(90.8)$ & 4 & (2.1) & 2 & $(1.0)$ & 12 & (6.2) \\
\hline Total & 2,736 & 2,500 & $(91.4)$ & 39 & (1.4) & 46 & $(1.7)$ & 151 & (5.5) \\
\hline \multicolumn{10}{|l|}{ Marital Status } \\
\hline Married & 2,152 & 1,956 & $(90.9)$ & 30 & (1.6) & 40 & (1.9) & 126 & (5.9) \\
\hline Divorced & 27 & 22 & $(81.5)$ & 1 & (3.7) & 0 & 0.0 & 4 & (14.8) \\
\hline Never married & 549 & 518 & $(94.4)$ & 4 & $(0.7)$ & 6 & $(1.1)$ & 21 & (3.8) \\
\hline Widowed & 8 & 4 & $(50.0)$ & 4 & (50) & 0 & 0.0 & 0 & 0.0 \\
\hline Total & 2,736 & 2,500 & $(91.4)$ & 39 & (1.4) & 46 & (1.7) & 151 & (5.5) \\
\hline
\end{tabular}


Drivers' knowledge of drink-driving law in Ghana

Of the drivers who were questioned, $97 \%$ answered in the affirmative regarding their knowledge of the drink-driving law in the country, whilst the remaining $3 \%$ said they did not know of any law regarding drink-driving. When drivers who said they knew the law were asked to state the legal alcohol limit, in terms of blood alcohol or by specifying the volume of alcohol an average person would need to drink to reach the limit, they could give neither a definitive blood-alcohol limit nor a quantity of drink. Fewer than $1 \%$ of drivers could even hazard a numerical legal alcohol limit, and the majority of these answers were not accurate.

\section{Police and drink-driving enforcement}

Generally, the police are ill-equipped to do meaningful enforcement, as the majority (98\%) of police stations visited did not have breathalyzers that were in good condition and could be used to test drivers' BrAC. When drivers were asked whether they had been tested recently on the road for BrAC, 96\% said they had never been tested since they started driving.

Table 2

\section{Predictors of drink-driving in Ghana}

\begin{tabular}{|c|c|c|c|c|c|}
\hline Variables & Observations & Logit & Odds Ratio & $P$ - value & $95 \%$ CI OR \\
\hline \multicolumn{6}{|l|}{ Vehicle Type } \\
\hline Bus & 1,352 & -0.192 & 0.825 & 0.406 & 0.52 to 1.30 \\
\hline Two-wheelers & 34 & 0.350 & 1.419 & 0.535 & 0.47 to 4.28 \\
\hline Cars & 838 & - & 1 & - & - \\
\hline Truck & 512 & 0.593 & 1.810 & 0.009 & 1.16 to 2.82 \\
\hline \multicolumn{6}{|l|}{ Educational Level } \\
\hline None & 165 & 0.612 & 1.845 & 0.012 & 1.14 to 2.98 \\
\hline Basic & 1,960 & - & 1 & - & - \\
\hline Secondary & 416 & 0.080 & 1.083 & 0.692 & 0.73 to 1.61 \\
\hline Tertiary & 195 & -0.231 & 0.793 & 0.447 & 0.44 to 1.44 \\
\hline \multicolumn{6}{|l|}{ Age } \\
\hline $18-29$ & 688 & 0.465 & 1.591 & 0.024 & 1.06 to 2.38 \\
\hline $30-39$ & 1,148 & 0.681 & 1.977 & 0.002 & 1.28 to 3.04 \\
\hline $40-49$ & 654 & - & 1 & - & - \\
\hline $50-59$ & 207 & 1.170 & 3.222 & 0.000 & 1.93 to 5.39 \\
\hline $60-72$ & 39 & 0.148 & 1.159 & 0.817 & 0.33 to 4.05 \\
\hline \multicolumn{6}{|l|}{ Day of Week } \\
\hline Saturday & 519 & - & 1 & - & - \\
\hline Sunday & 233 & -0.314 & 0.730 & 0.244 & 0.43 to 1.24 \\
\hline Monday & 196 & -0.444 & 0.642 & 0.154 & 0.35 to 1.18 \\
\hline Tuesday & 142 & -0.727 & 0.483 & 0.065 & 0.22 to 1.05 \\
\hline Wednesday & 257 & 0.318 & 1.375 & 0.158 & 0.88 to 2.14 \\
\hline Thursday & 651 & -0.803 & 0.448 & 0.000 & 0.29 to 0.70 \\
\hline Friday & 738 & -0.536 & 0.585 & 0.008 & 0.39 to 0.87 \\
\hline \multicolumn{6}{|l|}{ Driver Category } \\
\hline Private & 598 & - & 1 & - & - \\
\hline Commercial & 2,138 & -0.527 & 0.590 & 0.021 & 0.38 to 0.92 \\
\hline Constant & & -2.234 & & 0.000 & \\
\hline
\end{tabular}

Determinants of drink-driving among Ghanaian drivers A multivariable logistic regression analysis showing significant predictors of drink-driving is displayed in Table 2.

Driving trucks was significantly associated with impaired driving ( $p=0.009$ ). The odds of being found drunk on the roadway were about two times higher among truck drivers than among car drivers ( $O R=1.8$; 95\% CI: 1.16 to 2.82). Having a formal education is a significant predictor of lower propensity for drink-driving. Compared with drivers who had a basic education, the likelihood of being drunk among drivers without any formal education was $O R=1.8$

Table 2 shows that age of drivers was a significant predictor of drink-driving. The younger age groups- 18 to 29 years, and 30 to 39 years - showed significantly higher likelihood of drink-driving than did the 40-to-49-year-olds $(O R=1.6$ and $O R=2.0$ respectively). Those aged 50 to 59 were also at a 3.2 chance of drink-driving compared with those aged 40 to $49(p<0.001)$. The likelihood for those aged 60 years and above to drink-drive was not, however, significantly different from those aged 40 to $49(p=0.817)$. (95\% CI: 1.14 to 2.98 ). 
Table 3

Association between drink-driving and road traffic injuries

\begin{tabular}{|c|c|c|c|c|}
\hline Variable & Logit & Odds Ratio & $P$ - value & $95 \%$ CI of logit \\
\hline Percentage of Drivers exceeding legal BAC Level & 0.0369 & 1.038 & 0.000 & $0.026-0.048$ \\
\hline Constant & -2.064 & & & -2.21 to -1.916 \\
\hline
\end{tabular}

With the exception of Wednesday, on most days of the week there appears to be less likelihood of drink-driving than there is on Saturday. The model predicts a lower propensity of drink-driving on Thursdays $(p<0.001)$ and Fridays $(p=0.008)$ than on Saturdays.

Finally, commercial car drivers had a $41 \%$ lower rate of drink-driving than private car drivers $(p=0.021)$.

\section{Relationship between drink-driving and road traffic crashes}

Crash data for 2010 were analyzed for the settlements and road sections where BrAC samples were collected. In total, 5,896 road traffic crashes occurred in the study areas, out of which 956 (16.2\%) were fatal, 1,253 (21.3\%) resulted in serious injuries requiring at least a 24-hour hospitalization, 1,983 (33.6\%) resulted in minor injuries which required only out-patient treatment, and 1,704 (28.9\%) resulted in property damage only. Only injury-related crashes were used in the model.

Table 3 shows a significant relationship between the proportion of drivers exceeding the legal BAC and road traffic fatalities $(p<0.001)$. On the whole, a $1 \%$ increase in the proportion of drivers exceeding the legal BAC is associated with a corresponding $4 \%$ increase in road traffic fatality (95\% CI $=3 \%$ to $5 \%$ ).

\section{Discussion}

The roadside prevalence of driving while intoxicated in Ghana is $5.5 \%$. This rate is high compared to other countries; similar studies have shown prevalence rates between 2.9\% and 3.7\% in the U.S. (Chou et al., 2005; Chou et al., 2008), and 2\% in Thailand (Ingsathit et al., 2009). Mock et al. (2001) reported an impaired driving rate of $7 \%$ in Ghana, which is statistically not different from the current prevalence rate. This is probably because of weak enforcement. Countries which have registered significant declines in drink-driving have achieved this through consistent enforcement of the drink-driving law. The success of enforcement is premised on deterrence theory, fundamental attributes of which are certainty of apprehension, and swiftness and severity of punishment (Freeman \& Watson, 2006, 2009; Watling \& Freeman, 2011; Watling, Palk, Freeman, \& Davey, 2010). It was determined in this study that over $95 \%$ of drivers have never been tested for alcohol on the roadway during their lifetime of driving, suggesting a low level of enforcement. Our study predicts a potential reduction of $4 \%$ in traffic fatalities associated with a $1 \%$ decline in the proportion of drink-driving. Thus, to achieve declines in drink-drivingrelated traffic crashes and fatalities, there should be increased random breath testing on the roadways.

The distribution of drivers who tested positive for alcohol reveals the prevalence of heavy drink-driving in Ghana. Three possible explanations might account for this distribution. Due to the low level of drink-driving enforcement, there is little fear of apprehension for driving under the influence of alcohol. Secondly, many people drink alcohol before their meals in this country. Drinking liquor with a high alcoholic content on an empty stomach may result in swift absorption of alcohol into the bloodstream and engender rapid drunkenness (Mock, Asiamah, \& Amegashie, 1998). This is captured in a popular saying in Twi (one of the widely spoken languages in Ghana), " $y \varepsilon$ bu didi" (literally meaning, "we drink alcohol to boost our appetite for eating food"). These drinks are normally local liquors, or concoctions of herbs combined with local alcohol, collectively called "bitters" in the Ghanaian parlance. Consumption of about $650 \mathrm{ml}$ of these local liquors at one sitting can result in death (Akyeampong, 1996; Asare Buadu, 2013). Again, unlike the developed countries, Ghana has not defined standard drink quantities on the labels of bottles of alcoholic beverages. Drivers do not know the number of standard drinks that will bring them to the legal BAC, or that are permissible for drivers. For instance, when drivers who tested positive for breath alcohol were asked about the number of drinks they had consumed, they answered that they had had two calabashes of palm wine, or two pots of pito, or three bottles of beer. These units of measure are too arbitrary and unscientific to be relied upon for determining the amount of alcohol an individual has consumed. It is therefore recommended that Ghana should define what a standard drink is in this context, and enforce that standard drink labels are embossed on each kind of drink on the market.

Formal education is associated with a significantly lower likelihood of drink-driving. It appears drivers with some formal education have a better understanding and appreciation of the impairing effects of alcohol and the concomitant higher risk of accidents than do drivers without formal education (Abikoye, 2012). It is recommended that drivers should be educated via the media on the legal BAC limit and the harmful effects of drinkdriving.

Contrary to the general perception that commercial drivers in Ghana have a higher propensity to drink and drive, private car drivers are the worst offenders. 
It was evident in our results that younger drivers have an elevated propensity towards drink-driving, compared with adults. In corroboration with findings from other countries, episodic drinking is associated with youth and has resulted in their over-involvement in alcohol-related crashes (Clarke, Ward, \& Truman, 2005). Some developed countries have therefore outlined strategies aimed at combating high rates of drink-driving in general, and among young drivers in particular. One such policy is increasing the minimum legal drinking age (MLDA) to 21 years or above. Research has found the MLDA to be successful in significantly reducing young drivers' alcoholrelated accident rates (Hingson, Heeren, Levenson, Jamanka, \& Voas, 2002; McCartt, Hellinga, \& Kirley, 2010; Tomas Dols et al., 2010; Wrechsler, Lee, Nelson, \& Lee, 2003; Zarajsek \& Shope, 2006). According to a study by Begg and Langley (2001), many young people mature from their youthful impulsivity after age 26; if by this time they have never tasted alcohol, they may end up not drinking alcohol at all throughout their lifetime.

\section{Conclusion}

A significant association between roadside alcohol prevalence and road traffic fatalities has been established. In order to reduce drink-driving prevalence and its attendant road traffic crashes, it is recommended that the country should scale up its randomized roadside breathtesting program; define standard drink quantities and disseminate this information to the populace through intensive media education; increase the minimum legal drinking age to 21 years; and reduce the legal BAC limit for youth to $0.05 \%$, from the current legal limit of $0.08 \%$. The prevailing legal BAC of $0.08 \%$ is on the high side; due to the apparent impairment at the $0.08 \%$ level, the country should consider reducing this level over the long term.

\section{Acknowledgement}

Funding was provided by the National Road Safety Commission (NRSC) of Ghana. Our gratitude goes to all the staff of the Building \& Road Research Institute (BRRI), who contributed in data gathering, analysis and secretarial support.

\section{References}

Abikoye, G. E. (2012). Psycho-spatial predictors of alcohol use among motor drivers in Ibadan, Nigeria: Implications for preventing vehicular accidents. International Journal of Alcohol and Drug Research, 1, 17-26.

Adu-Mireku, S. (2003). The prevalence of alcohol, cigarette, and marijuana use among Ghanaian senior secondary students in an urban setting. Journal of Ethnicity in Substance Abuse, 2, 53-65.

Akyeampong, E. (1996). What's in a drink? Class struggle, popular culture and the politics of akpeteshie (local gin) in Ghana, 1930-1967. Journal of African History, 37, 215-236.
Asare Buadu, K. (2013). Man dies after akpeteshie contest. Daily Graphic. Retrieved from http://graphic.com.gh/ archive/General-News/man-dies-after-akpeteshiecontest.html

Begg, D., \& Langley, J. (2001). Changes in risky driving behavior from age 21 to 26 years. Journal of Safety Research, 32, 491-499.

Building \& Road Research Institute (BRRI). (2011). Road traffic crashes in Ghana, statistics 2010. National Road Safety Commission.

Chang, K. Y., Wu, C. C., \& Ying, Y. H. (2012). The effectiveness of alcohol control policies on alcoholrelated traffic fatalities in the United States. Accident Analysis and Prevention, 45, 406-415. doi: 10.1016/j.aap.2011.08.008

Chou, P. S., Dawson, D. A., Stinson, F. S., Huang, B., Saha, T., Pickering, R. P., . . Grant, B. F. (2005). The prevalence of drinking and driving in the United States, 2001-2002: Results from the national epidemiological survey on alcohol-related conditions. Drug and Alcohol Dependence, 83, 346-350.

Chou, P. S., Grant, B. F., Dawson, D. A., Stinson, F. S., Saha, T., \& Pickering, R. P. (2008). Twelve-month prevalence of drinking and driving: United States, 1991-1992 and 2001-2002. Drug and Alcohol Dependence, 80, 223-230.

Clarke, D. D., Ward, P., \& Truman, W. (2005). Voluntary risk taking and deficits in young drivers in the U.K. Accident Analysis \& Prevention, 37, 523-529.

Cowan, J. M., Burris, J. M., Hughes, J. R., \& Cunningham, M. P. (2010). The relationship of normal body temperature, end-expired breath temperature, and BAC/BrAC ratio in 98 physically fit human test subjects. Journal of Analytical Toxicology, 34, 238242.

Doku, D., Koivusilta, L., \& Rimpela, A. (2012). Socioeconomic differences in alcohol and drug use among Ghanaians adolescents. Addictive Behaviors, 37, 357-360.

Freeman, J., \& Watson, B. (2006). An application of Stafford and Warr's reconceptualisation of deterrence to a group of recidivist drink-drivers. Accident Analysis \& Prevention, 38, 462-471.

Freeman, J., \& Watson, B. (2009). Drink-driving deterrents and self-reported offending behaviours among a sample of Queensland motorists. Journal of Safety Research, 40, 113-120.

Global Road Safety Partnership. (2007). Drinking and driving: A road safety manual for decision-makers and practitioners. Geneva, Switzerland: Author.

Haffner, H. T., Graw, M., Dettling, A., Schmitt, G., \& Schuff, A. (2003). Concentration dependency of the BAC/BrAC (blood alcohol concentration/breath alcohol concentration) conversion factor during the linear elimination phase. International Journal of Legal Medicine, 117, 276-281. doi:10.1007/s00414003-0384-5

Hingson, R., Heeren, T., Levenson, S., Jamanka, A., \& Voas, R. (2002). Age of drinking onset, driving after drinking, and involvement in alcohol related motorvehicle crashes. Accident Analysis \& Prevention, 34, 85-92. doi:10.1016/s0001-4575(01)00002-1 
Ingsathit, A., Woratanarat, P., Anukarahanonta, T., Rattanasiri, S., Chatchaipun, P., Wattayakorn, K., ... Suriyawongpaisal, P. (2009). Prevalence of psychoactive drug use among drivers in Thailand: A roadside survey. Accident Analysis \& Prevention, 41, 474-478. doi:10.1016/j.aap.2009.01.010

Longo, M. C., Hunter, C. E., Lokan, R. J., White, J. M., \& White, M. A. (2000). The prevalence of alcohol, cannabinoids, benzodiazepines and stimulants amongst injured drivers and their role in driver culpability: Part II: The relationship between drug prevalence and drug concentration, and driver culpability. Accident Analysis \& Prevention, 32, 623632. doi:10.1016/s0001-4575(99)00110-4

McCartt, A. N., Hellinga, L. A., \& Kirley, B. B. (2010). The effects of minimum legal drinking age 21 laws on alcohol-related driving in the United States. Journal of Safety Research, 41, 173-181.

Mock, C., Asiamah, G., \& Amegashie, J. (1998, October). Epidemiology of alcohol impaired driving in an African nation. Paper presented at the 42nd Annual Meeting of the Association for the Advancement of Automotive Medicine, Charlottesville, VA.

Mock, C., Asiamah, G., \& Amegashie, J. (2001). A random roadside breathalyzer survey of alcohol impaired driving in Ghana. Journal of Crash Prevention and Injury Control, 2, 193-202.

Obot, I. S. (2000). The measurement of drinking patterns and alcohol problems in Nigeria. Journal of Substance Abuse, 12, 169-181.

Owusu Achiaw, N., \& Donkor, M. (2007, Thursday, November 15). Miraculous escape: President unhurt in horrific crashes. Daily Graphic, p. 1.

Peden, M., Scurfield, R., Sleet, D., Mohan, D., Hyder, A. A., Jarawan, E., \& Mathers, C. (2004). World report on road traffic injury prevention. Geneva, Switzerland: World Health Organization.

Salifu, M., \& Ackaah, W. (2009). Under-reporting of road traffic crash data in Ghana. Paper presented at the 4th IRAD Conference, Seoul, Korea. www.internationaltransportforum.org/itrad.pdf/seoul/4 -salifu.pdf

Tomas Dols, S., González, F. J. Á., Aleixandre, N. L., Vidal-Infer, A., Rodrigo, M. J. T., \& ValderramaZurián, J. C. (2010). Predictors of driving after alcohol and drug use among adolescents in Valencia (Spain). Accident Analysis \& Prevention, 42, 2024-2029. doi:10.1016/j.aap.2010.06.013

University of Dundee. (2011). Lecture notes: alcohol and alcoholism. Department of Forensic Medicine. Retrieved from: www.dundee.ac/forensicmedicines/ notes/alcohol.pdf

UNODC. (2013). World Drug Report 2013. from www.unodc.org

Watling, C. N., \& Freeman, J. (2011). Exploring the theoretical underpinnings of driving whilst influenced by illicit substances. Transportation Research Part F: Traffic Psychology and Behaviour, 14, 567-578. doi:10.1016/j.trf.2011.06.002

Watling, C. N., Palk, G. R., Freeman, J. E., \& Davey, J. D. (2010). Applying Stafford and Warr's reconceptualization of deterrence theory to drug driving: Can it predict those likely to offend? Accident Analysis \& Prevention, 42, 452-458. doi:10.1016/ j.aap.2009.09.007

Wells, S., \& Macdonald, S. (1999). The relationship between alcohol consumption patterns and car, work, sports and home accidents from different age groups. Accident Analysis \& Prevention, 31, 663-665.

World Health Organization (WHO). (2009). Global Status Report on Road Safety: Time for Action (D. O. V. I. Prevention, Trans.). Geneva, Switzerland: Author.

World Health Organization (WHO). (2011). Road traffic injuries. Facts Sheet Retrieved from http://www.who.int/mediacentre/factsheets/fs358/en

Wrechsler, H., Lee, J. E., Nelson, T. F., \& Lee, H. (2003). Drinking and driving among college students: The influence of alcohol control policies. American Journal of Preventive Medicine, 25, 212-218.

Zarajsek, J. S., \& Shope, J. T. (2006). Longitudinal examination of underage drinking and subsequent drinking. Journal of Safety Research, 37, 443-451. 